\title{
Development of Novel Chalcone Analogs as Potential Multi- Targeted Therapies for Castration-Resistant Prostate Cancer
}

\section{Ola Hussein'1, Feras Alali', Ala-Eddin Al Mustafa ${ }^{2,3}$, Ashraf Khalil'}

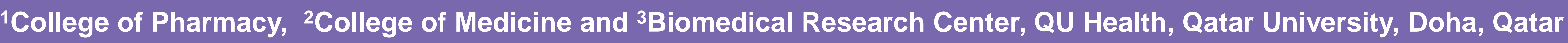

\section{Backgrousel}

- Prostate cancer (PCa) is the second most frequently diagnosed malignancy and a leading cause of cancer-related mortality in men globally

- Despite the initial improvement to hormone targeted therapy, most patients ultimately develop resistance

- Castration resistant prostate cancer is associated with poor prognosis and available therapies cannot prolong survival for more than 5 months.

- Chalcones (C6-C3-C6) are highly attractive scaffolds that posses a wide variety of biological activities

\section{Objectives}

1. Design, synthesize and elucidate the structure of novel chalcone analogs

2. Evaluate their in-vitro anticancer activity and in-ovo antiangiogenic effect

\section{Wethods}

(Confirm Novelty using SciFinder)<smiles>C1CC1</smiles>

In Silico ADMET Screening (Swiss ADME and ADMET Predictor")

$=0$ Synthesis Chemical Synthesis
(Using Claisen-Schmidt condensation reaction)

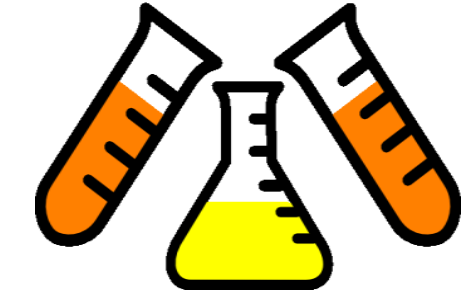

Chemical Purification (Flash chromatography, recrystallization, prep-HPLC) $\downarrow$

Structure Elucidation

$\left({ }^{1} \mathrm{H}\right.$ and ${ }^{13} \mathrm{C}$ NMR, LCMS, elemental analysis, FT-IR)

Biological Evaluation Compounds 1-16 Compounds 16-26

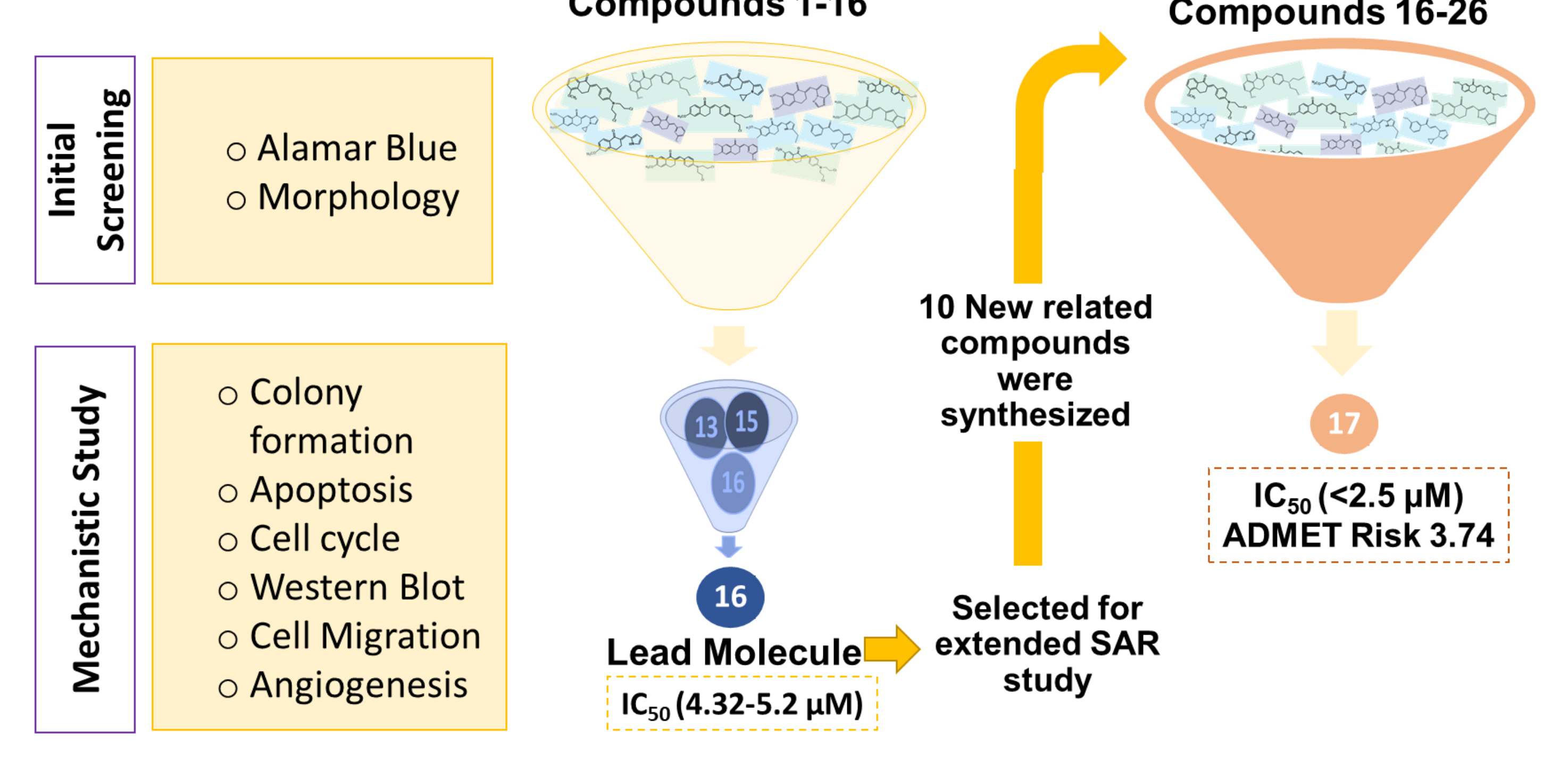

A.

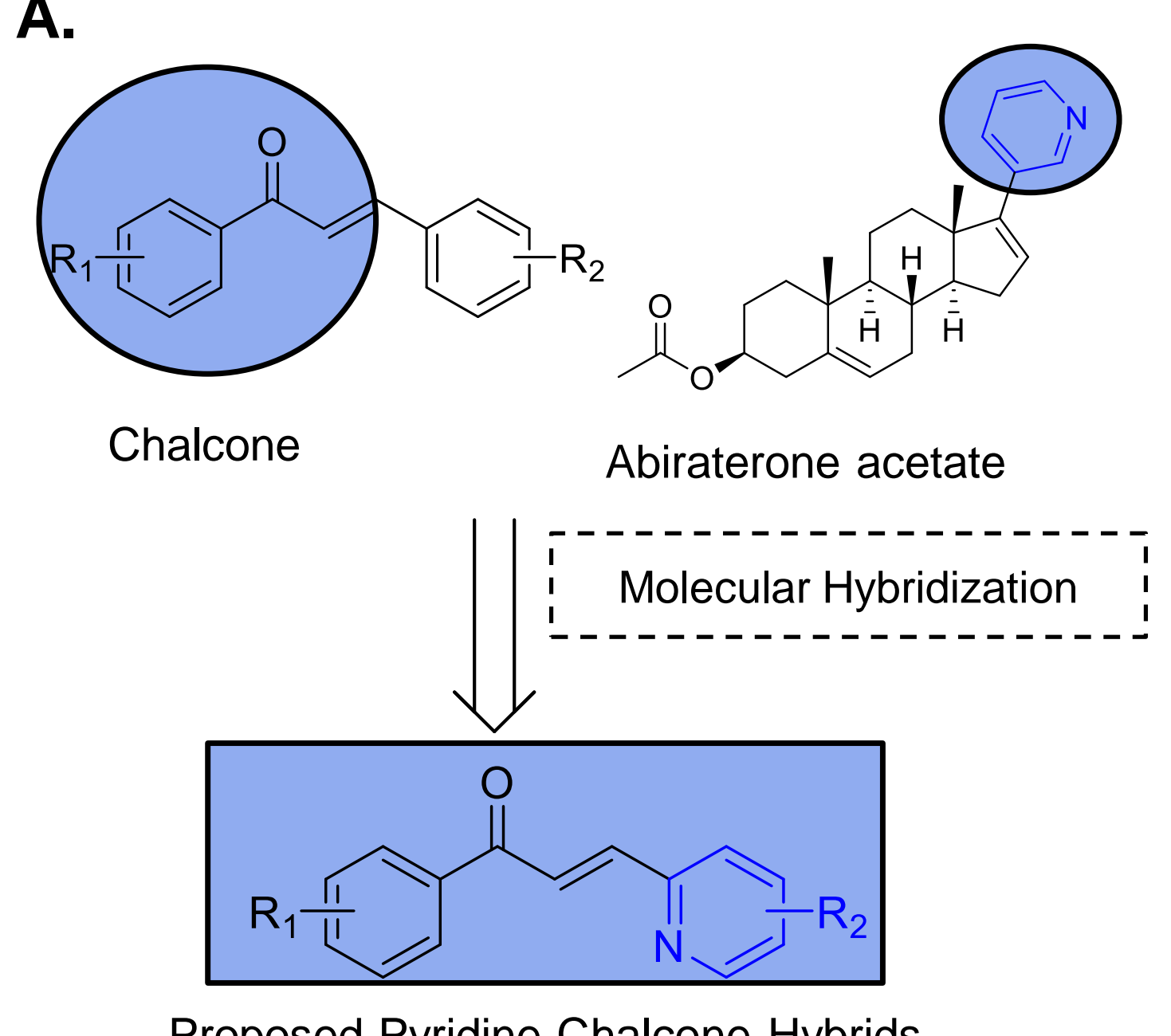

$$
\text { Proposed Pyridine-Chalcone Hybrics }
$$

$\mathrm{R} 1=\mathrm{OCH}_{3}, \mathrm{OH}_{1} \mathrm{CF}_{3}, \mathrm{SO}_{2} \mathrm{CH}_{3}$

\section{B.}

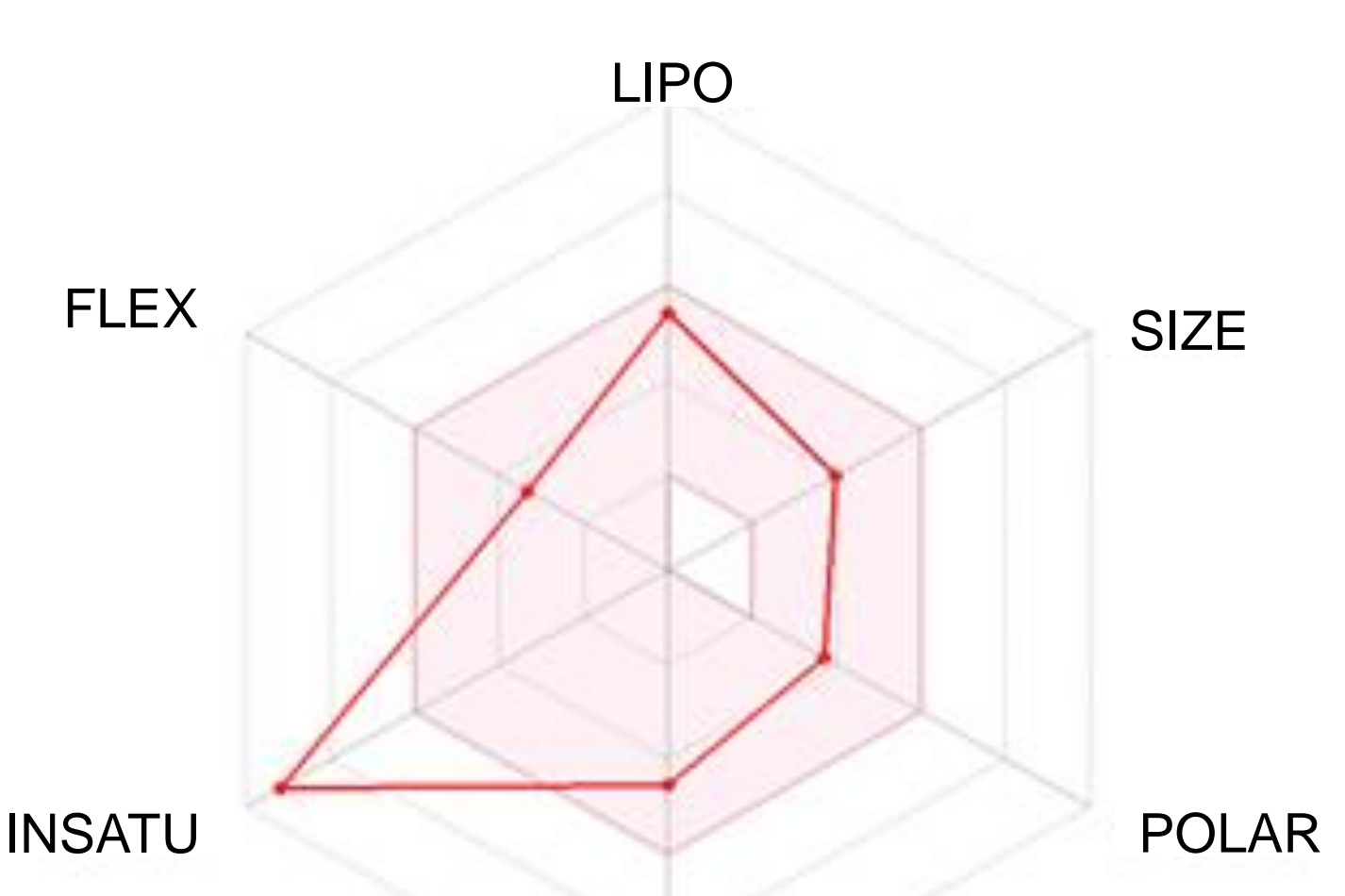

\section{Resulits}

A) PC3 Cell Viability (48h)

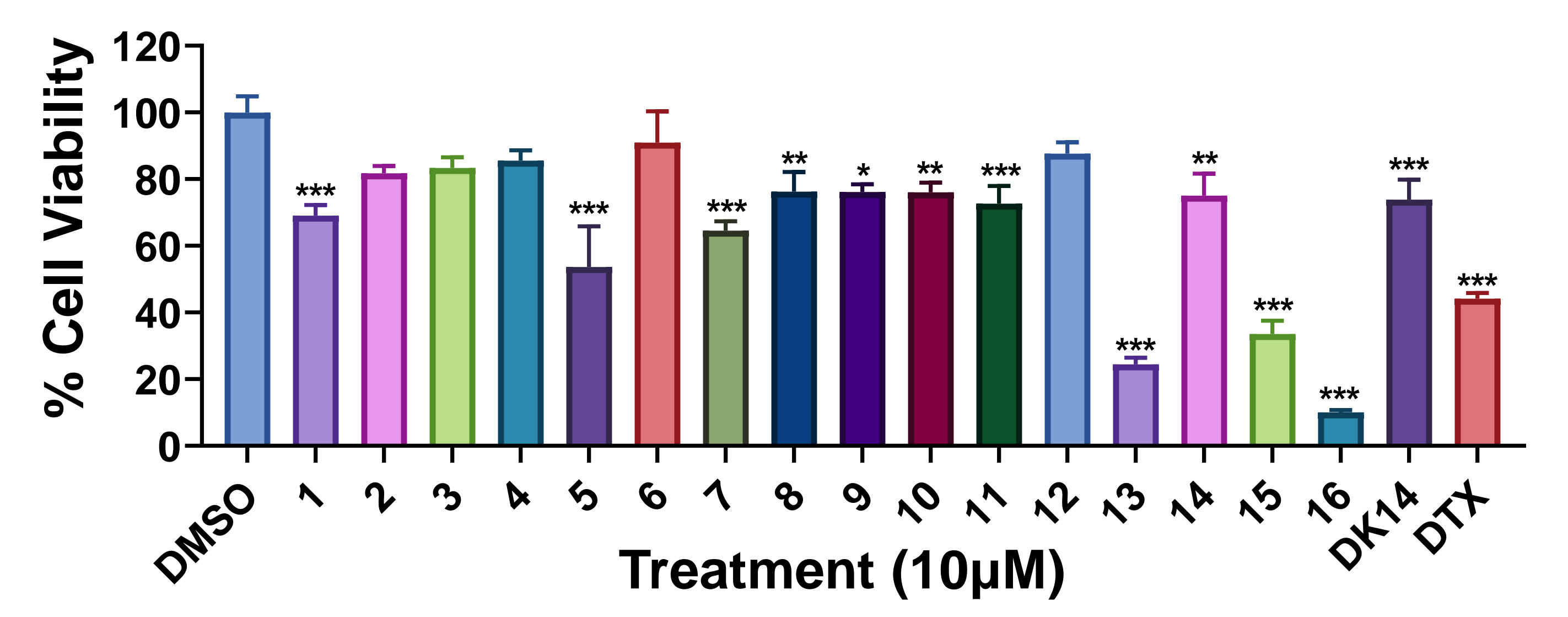

Figure 2. Effect of compounds 1-16 on the cell viability of PC3. Values are expressed as mean \pm SEM. ${ }^{*} \mathrm{P}<0.01,{ }^{*} \mathrm{P}<0.001$ vs. control (A). Dose response curve against $\mathrm{PC} 3$ for the most potent analogs (B).
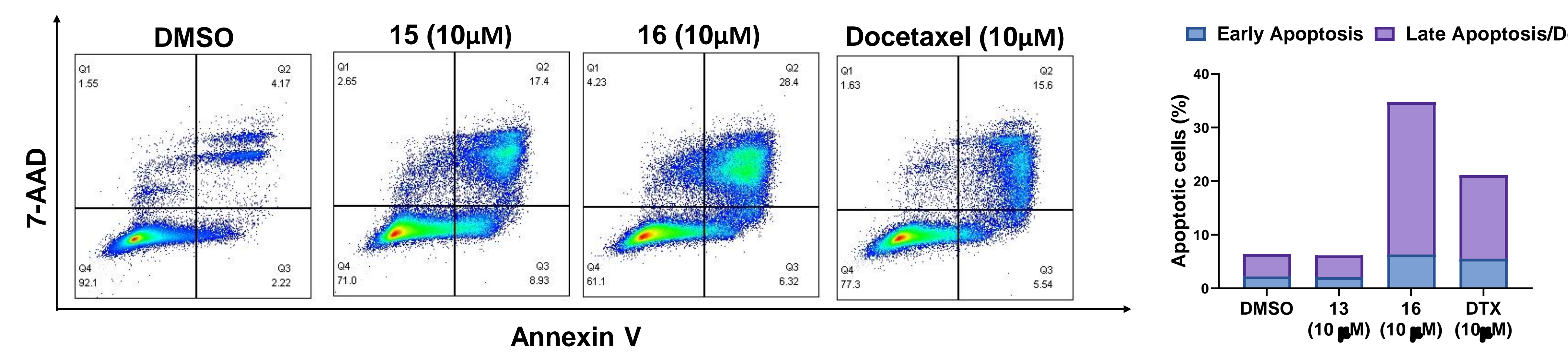

Figure 3. Effect of compounds 15 and 16 on apoptosis of PC 3 cells.

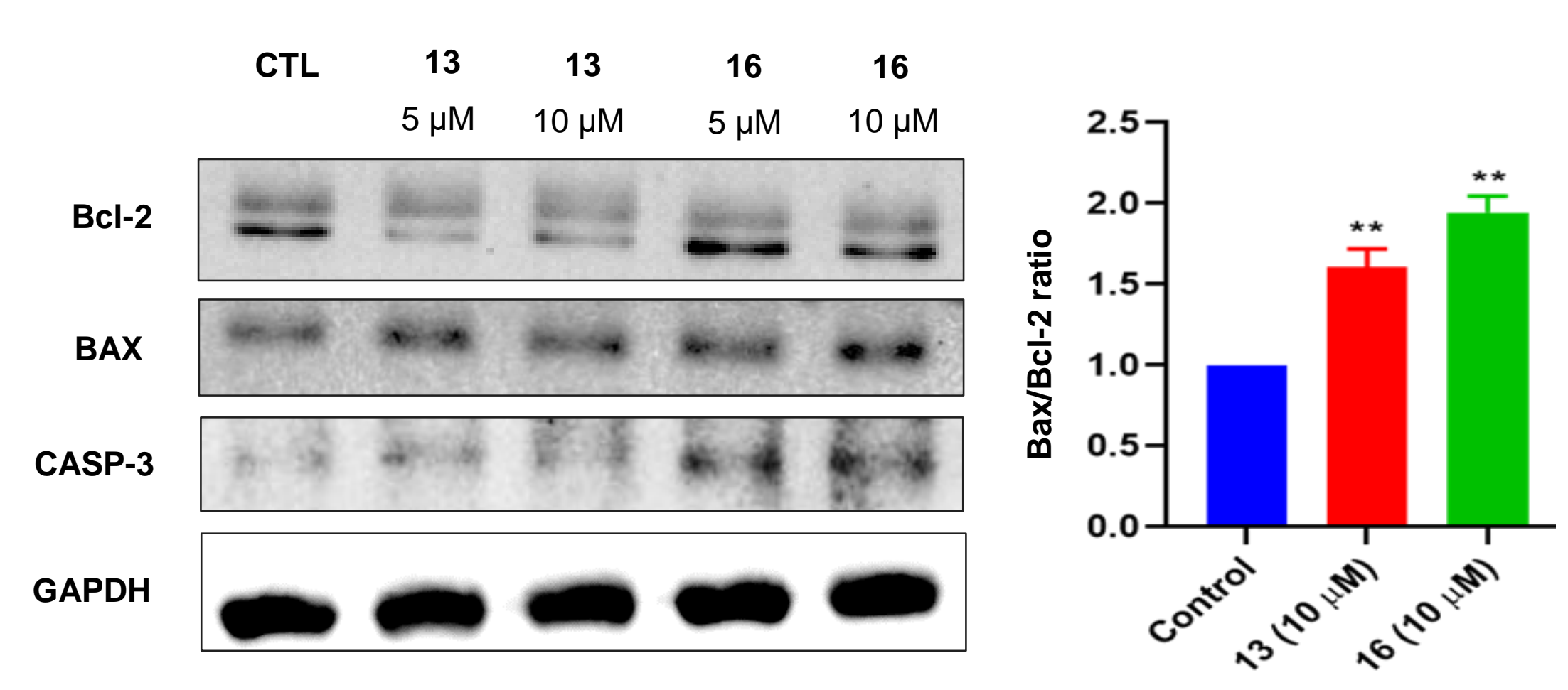

Figure 4. Effect of compounds 13 and 16 on apoptosis related proteins in PC3 cells.

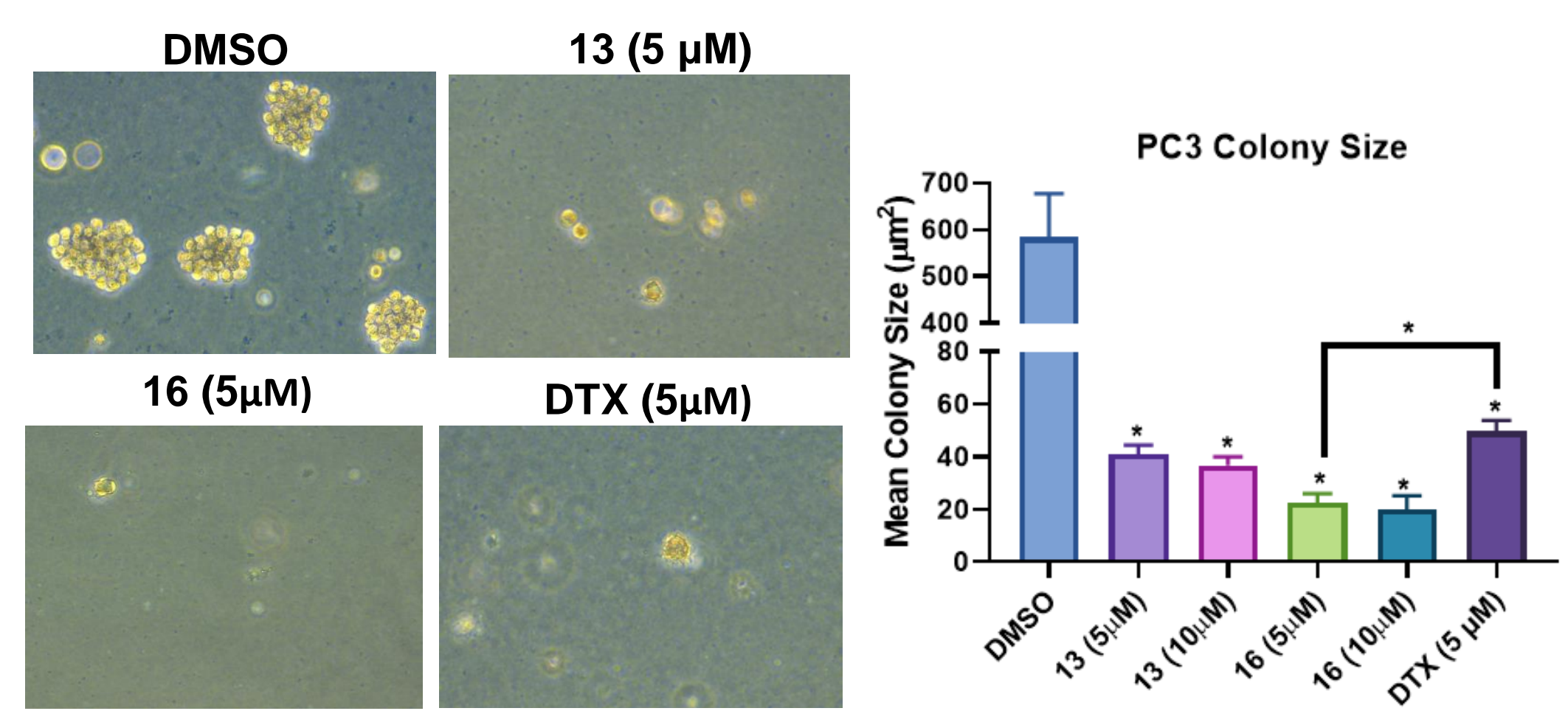

DMSO
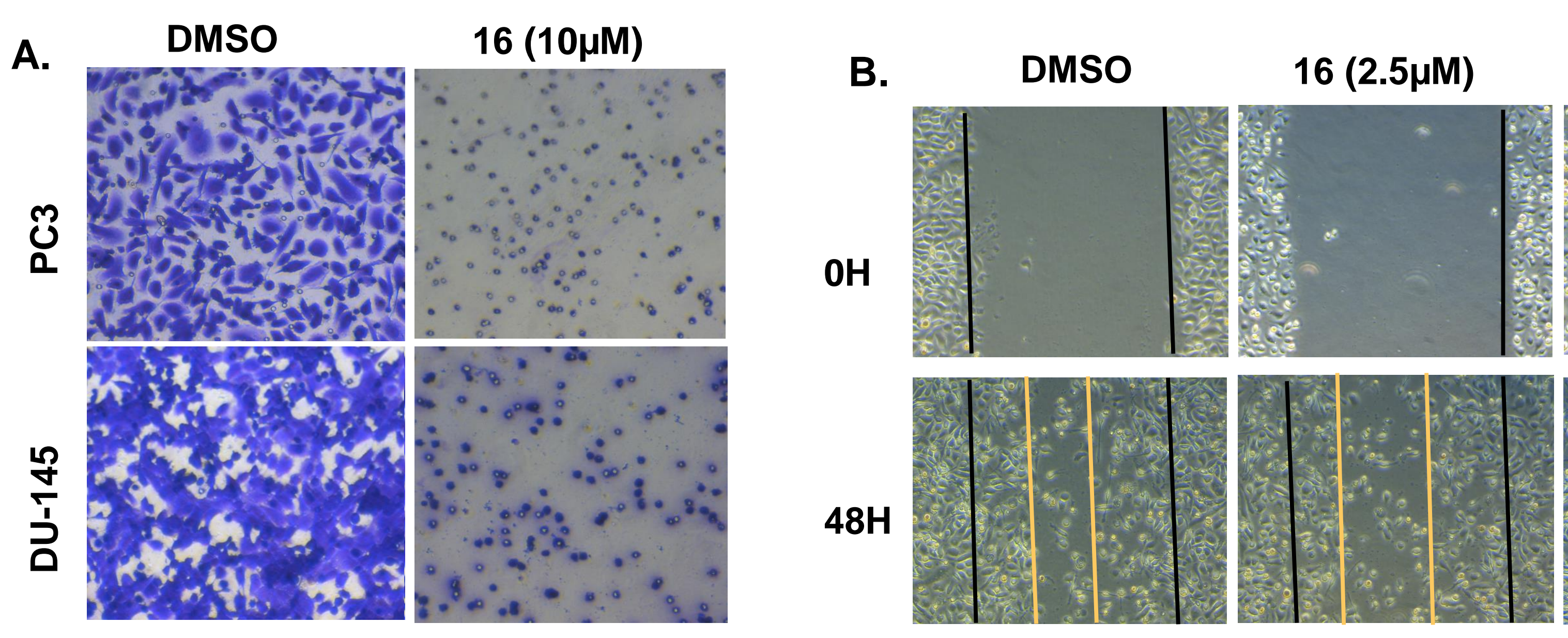

Figure 5. Effect of compound 16 on soft agar colony formation of PC3 cells.

Figure 6. Effect of compound 16 on trans well- (A) and wound healing-(B) migration assays.
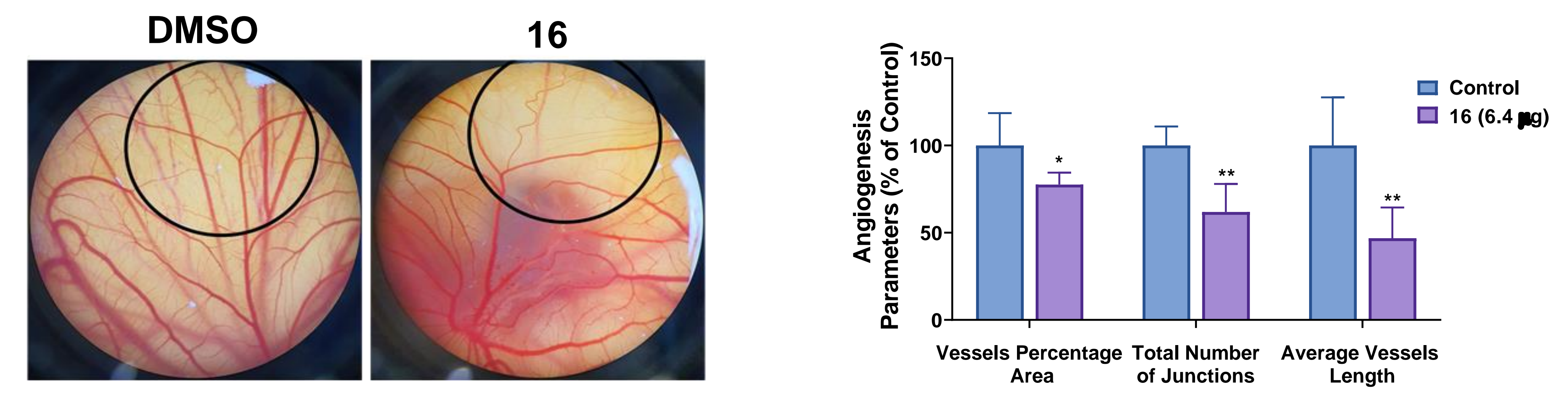

Figure 7. Effect of compound 16 on Angiogenesis of the CAM of chicken embryos after 48 hours of treatment. The encircled zone marks the treated area

\section{Conclusion}

- Twenty-six novel chalcone analogs were designed and synthesized

- Compounds 13, 15 and 16 showed potent antiproliferative activities at low micromolar levels with $\mathrm{IC}_{50}$ values ranging between 4.3 and 6.6 $\mu \mathrm{M}$ against PC3 and DU145 cell lines

- Compound 16 significantly inhibited colony formation, migration and angiogenesis and induced apoptosis

\section{Future Direction}

- These results indicate that compound 16 could serve a potential promising lead molecule for the treatment of $\mathrm{PCa}$ and thus, further in vivo studies are warranted.

\section{AGknOWledgenent}

- Our research work is supported by Grant\# QUCG-CPH20/21-4 from Qatar University.

The NMR, LC-MS and FT-IR were accomplished in the Central Laboratories unit, Qatar University. 